\title{
The incidence and prognostic value of silent myocardial scar by late gadolinium enhancement in patients with atrial fibrillation
}

\author{
Tomas G Neilan ${ }^{2,1}$, Hoshang Farhad ${ }^{1 *}$, Ravi Shah ${ }^{1,2}$, Siddique Abbasi ${ }^{1}$, Otavio R Coelho-Filho ${ }^{5}$, John D Groarke ${ }^{1}$, \\ Ciaran J McMullann ${ }^{4}$, Bobby Heydari ${ }^{1}$, Michael L Steigner ${ }^{3}$, Ron Blankstein ${ }^{1}$, Michael Jerosch-Herold ${ }^{3}$, \\ Raymond Y Kwong ${ }^{1}$
}

From 16th Annual SCMR Scientific Sessions

San Francisco, CA, USA. 31 January - 3 February 2013

\section{Background}

Late gadolinium enhancement (LGE) during contrastenhanced cardiac magnetic resonance (CMR) imaging is a powerful predictor of adverse event. However, there are limited data regarding the incidence and prognostic significance of LGE in patients with atrial fibrillation (AF). Furthermore, while CMR is one of the modalities employed in characterizing pulmonary venous anatomy in patients being considered for radiofrequency ablation therapy, the prognostic significance of an incidental finding of abnormal LGE is unclear. Therefore, our study has 2 aims: 1 ) to identify the frequency of unanticipated LGE in patients with AF and 2) to determine whether identification of LGE in this population could provide important prognostic information.

\section{Methods}

We performed clinical follow-up on 675 consecutive patients referred for a CMR in preparation for pulmonary vein isolation between September 2005 and March 2011. The clinical end-point of interest was all-cause mortality. Patients with prior myocardial infarction (MI) by clinical history or EKG were excluded. Considering all the significant variables on univariable analysis, we sought the bestoverall multivariate models for patient mortality. After excluding patients with MI by clinical history or EKG, all patients were included with all distributions of LGE.

\section{Results}

Fifty five patients (8\%) had evidence of a prior MI and were excluded. Of the remaining 620 patients, $73 \%$ were male with an average age of 56 years, a BMI of $30 \pm 5$ $\mathrm{kg} / \mathrm{m} 2$, a left ventricular (LV) end-diastolic volume of $167 \pm 42 \mathrm{mls}$, an LV mass index of $65 \pm 12 \mathrm{gms} / \mathrm{m} 2$, and a LV ejection fraction of $56 \pm 10 \%$. Of these, 311 patients (50\%) had a history of hypertension, 96 (15\%) had diabetes, 120 (19\%) had sleep apnea, and $156(25 \%)$ had a history of heart failure. LGE was found in 80 patients (13\%). There were 61 deaths over a median follow-up period of 42 months. On univariable analysis, age (HR 1.03, CI 1.00-1.06, chi-squared 5.83, $\mathrm{P}=0.02$ ), diabetes (HR 2.51, CI 1.44-4.36, chi-squared 10.6, $\mathrm{P}=0.001$ ), heart failure (HR 1.72, CI 1.02-2.90, chi-squared 4.1, $\mathrm{P}=0.04$ ), the presence of LGE (HR 8.52, CI 4.18-12.2, chi-squared 25.8, $\mathrm{P}<0.0001$ ), and the extent of LGE (HR 1.15, CI 1.10-1.21, chi-squared 35.6, $\mathrm{P}<0.0001$ ) provided the strongest association with mortality. In a multivariate model, LGE was the strongest multivariable predictor of mortality. Each adjusted 1\% increase in LGE was associated with a $15 \%$ increased risk of death.

\section{Conclusions}

In patients with atrial fibrillation and without a prior history of MI, LGE is a frequent finding and is a powerful predictor of mortality. These data support the robust prognostic value of CMR for patients prior to radiofrequency ablation of atrial fibrillation, and support the need for further workup in patients with high-risk findings. 


\section{Funding}

This work was supported in part by an American Heart Association Fellow to Faculty Grant (12FTF12060588, TGN), a National Institute of Health T32 Training Grant (T32HL09430101A1, TGN), and project grants (R01HL090634-01A1, MJH; R01HL091157, RYK).

\section{Author details}

'Cardiology, Brigham and Women's Hospital/Massachusetts General Hospital, Boston, MA, USA. ${ }^{2}$ Cardiology, Massachusetts General Hospital, Boston, MA,

USA. ${ }^{3}$ Radiology, Brigham and Women's Hospital, Boston, MA, USA.

${ }^{4}$ Nephrology, Brigham and Women's Hospital, Boston, MA, USA. Internal

Medicine, State University of Campinas (UNICAMP), Sao Paulo, Brazil.

Published: 30 January 2013

doi:10.1186/1532-429X-15-S1-P259

Cite this article as: Neilan et al:: The incidence and prognostic value of silent myocardial scar by late gadolinium enhancement in patients with atrial fibrillation. Journal of Cardiovascular Magnetic Resonance 2013 15(Suppl 1):P259

Submit your next manuscript to BioMed Central and take full advantage of:

- Convenient online submission

- Thorough peer review

- No space constraints or color figure charges

- Immediate publication on acceptance

- Inclusion in PubMed, CAS, Scopus and Google Scholar

- Research which is freely available for redistribution

Submit your manuscript at www.biomedcentral.com/submit 